\title{
Adherence to subcutaneous immunotherapy with aeroallergens in real-life practice during the COVID-19 pandemic
}

\author{
Osman Ozan Yeğit ${ }^{1}$, semra demir ${ }^{1}$, Derya Erdoğdu르, Muge Olgac ${ }^{3}$, Kadriye Terzioğlu ${ }^{4}$, \\ Deniz Eyice Karabacak ${ }^{1}$, Can Tuzer ${ }^{1}$, Vehbi Ayhan ${ }^{2}$, Bahattin Çolakoğlu ${ }^{1}$, Suna \\ Büyüköztürk ${ }^{1}$, and Aslı Gelincik ${ }^{1}$ \\ ${ }^{1}$ Istanbul University Istanbul Faculty of Medicine \\ ${ }^{2}$ Yedikule Chest Diseases and Thoracic Surgery Training and Research Hospital \\ ${ }^{3}$ Sisli Hamidiye Etfal Training and Research Hospital \\ ${ }^{4}$ Kartal Dr Lütfi Kırdar Training and Research Hospital
}

February 5, 2021

\begin{abstract}
Background: The success of subcutaneous immunotherapy (SCIT) mostly depends on regular injections. Our aim was to investigate adherence to SCIT with aeroallergens during the COVID-19 pandemic and demonstrate clinical consequences of treatment disruptions in real-life. Methods: Visual analogue scale for quality of life (VAS-QoL), VAS for symptom scores (VAS-symptom), medication scores (MSs) and total symptom scores (TSS-6) were recorded during the pandemic in 327 adult allergic rhinitis and/or asthmatic patients receiving maintenance SCIT and these scores were compared with the pre-pandemic data. Patients were grouped according to SCIT administration intervals; no delay (Group 1), $<2$ months (Group 2), and [?]2 month intervals (Group 3). Results: 104 (31.8\%) patients (Group 3) were considered as non-adherent which was mostly related to receiving SCIT with HDMs and using public transportation for reaching the hospital. Median MS, VAS-symptom and TSS-6 scores of Group 3 patients during the pandemic were higher than the pre-pandemic scores $(\mathrm{p}=0.005, \mathrm{p}<0.001$, $\mathrm{p}<0.001$, respectively) whereas median VAS-QoL scores of Group 3 during the pandemic were lower than the pre-pandemic scores $(\mathrm{p}<0.001)$. Median TSS-6 and VAS-symptom scores were the highest in Group 3 compared to other groups ( $\mathrm{p}<0.001$ for each comparison). Median VAS-QoL scores were the lowest in Group 3 compared to Group 1 and Group 2 ( $\mathrm{p}<0.001, \mathrm{p}=0.043$, respectively). Conclusion: When precautions in allergy clinics are carefully applied, adherence to SCIT can be high during a pandemic. Patients must be warned about adhering to SCIT injections since delays in SCIT administration can deteriorate clinical symptoms.
\end{abstract}

\section{Title page}

Adherence to subcutaneous immunotherapy with aeroallergens in real-life practice during the COVID-19 pandemic

\section{Running Title: COVID-19 and adherence to subcutaneous immunotherapy}

Osman Ozan Yeğit ${ }^{1}$, Semra Demir ${ }^{1}$, Derya Ünal ${ }^{2}$, Müge Olgaç$^{3}$, Kadriye Terzioğlu ${ }^{4}$, Deniz Eyice ${ }^{1}$, Can Tüzer $^{1}$, Vehbi Ayhan ${ }^{2}$, Bahauddin Çolakoğlu ${ }^{1}$, Suna Büyüköztürk ${ }^{1}$, Aslı Gelincik ${ }^{1{ }^{*}}$

${ }^{1}$ Division of Immunology and Allergic Diseases, Department of Internal Medicine, Istanbul Faculty of Medicine, Istanbul University, Istanbul, Turkey

2 Adult Immunology and Allergy Clinic, Yedikule Chest Diseases and Thoracic Surgery Education and Research Hospital, Istanbul, Turkey 
${ }^{3}$ Adult Immunology and Allergy Clinic, Şişli Hamidiye Etfal Education and Research Hospital, Istanbul, Turkey

${ }^{4}$ Adult Immunology and Allergy Clinic, Kartal Dr Lütfi Kırdar Education and Research Hospital, Istanbul, Turkey

\section{*Corresponding Author:}

\section{Aslı Gelincik}

Division of Immunology and Allergic Diseases, Department of Internal Medicine, Istanbul Faculty of Medicine, Istanbul University, Istanbul, Turkey

Tel: +902124142000-32823 Fax: +90 2126358522

Turgut Ozal Millet Cd, 34093, Fatih, Istanbul, Turkey

gelincikasli@hotmail.com

Funding source: None

Word count: 245 for abstract, 3496 for manuscript

\section{Author contributions:}

Osman Ozan Yeğit has made substantial contributions to conception and design, or acquisition of data, or analysis and interpretation of data; has been involved in drafting the manuscript or revising it critically for important intellectual content.

Semra Demir has made substantial contributions to conception and design, or acquisition of data, or analysis and interpretation of data; has been involved in drafting the manuscript or revising it critically for important intellectual content.

Derya Ünal has made substantial contributions to conception and design, or acquisition of data, or analysis and interpretation of data; has been involved in drafting the manuscript or revising it critically for important intellectual content.

Müge Olgaç has made substantial contributions to conception and design, or acquisition of data, or analysis and interpretation of data; has been involved in drafting the manuscript or revising it critically for important intellectual content.

Kadriye Terzioğlu has made substantial contributions to conception and design, or acquisition of data, or analysis and interpretation of data; has been involved in drafting the manuscript or revising it critically for important intellectual content.

Deniz Eyice has made substantial contributions to conception and design, or acquisition of data, or analysis and interpretation of data; has been involved in drafting the manuscript or revising it critically for important intellectual content.

Can Tüzer has made substantial contributions to conception and design, or acquisition of data, or analysis and interpretation of data; has been involved in drafting the manuscript or revising it critically for important intellectual content.

Vehbi Ayhan has made substantial contributions to conception and design, or acquisition of data, or analysis and interpretation of data; has been involved in drafting the manuscript or revising it critically for important intellectual content.

Bahauddin Çolakoğlu has made substantial contributions to conception and design, or acquisition of data, or analysis and interpretation of data; has been involved in drafting the manuscript or revising it critically for important intellectual content. 
Suna Büyüköztürk has made substantial contributions to conception and design, or acquisition of data, or analysis and interpretation of data; has been involved in drafting the manuscript or revising it critically for important intellectual content.

Aslı Gelincik has made substantial contributions to conception and design, or acquisition of data, or analysis and interpretation of data; has been involved in drafting the manuscript or revising it critically for important intellectual content.

\section{ABSTRACT:}

Background: The success of subcutaneous immunotherapy (SCIT) mostly depends on regular injections. Our aim was to investigate adherence to SCIT with aeroallergens during the COVID-19 pandemic and demonstrate clinical consequences of treatment disruptions in real-life.

Methods : Visual analogue scale for quality of life (VAS-QoL), VAS for symptom scores (VAS-symptom), medication scores (MSs) and total symptom scores (TSS-6) were recorded during the pandemic in 327 adult allergic rhinitis and/or asthmatic patients receiving maintenance SCIT and these scores were compared with the pre-pandemic data. Patients were grouped according to SCIT administration intervals; no delay (Group 1), $<2$ months (Group 2), and [?]2 month intervals (Group 3).

Results : $104(31.8 \%)$ patients (Group 3) were considered as non-adherent which was mostly related to receiving SCIT with HDMs and using public transportation for reaching the hospital. Median MS, VASsymptom and TSS- 6 scores of Group 3 patients during the pandemic were higher than the pre-pandemic scores ( $\mathrm{p}=0.005, \mathrm{p}<0.001, \mathrm{p}<0.001$, respectively) whereas median VAS-QoL scores of Group 3 during the pandemic were lower than the pre-pandemic scores $(\mathrm{p}<0.001)$. Median TSS-6 and VAS-symptom scores were the highest in Group 3 compared to other groups ( $\mathrm{p}<0.001$ for each comparison). Median VAS-QoL scores were the lowest in Group 3 compared to Group 1 and Group 2 ( $\mathrm{p}<0.001, \mathrm{p}=0.043$, respectively).

Conclusion: When precautions in allergy clinics are carefully applied, adherence to SCIT can be high during a pandemic. Patients must be warned about adhering to SCIT injections since delays in SCIT administration can deteriorate clinical symptoms.

Keywords: Adherence, COVID-19, pandemic, real-life study, subcutaneous immunotherapy

\section{INTRODUCTION:}

On March 11, 2020 when the World Health Organization (WHO) declared the 'corona virus disease 2019' (COVID-19) a pandemic, the first case was announced by the Ministry of Health in Turkey. COVID-19 pandemic itself and the social restriction measures applied to control the transmission of the virus have influenced many areas of medical interventions including ongoing treatments of chronic diseases all over the world. Meanwhile statements from specific health organisations have been announced to warn patients and healthcare professionals about the importance of maintaining such treatments under many different clinical conditions. Similarly, a recent Allergic Rhinitis and its Impact on Asthma (ARIA)-European Academy for Allergy and Clinical Immunology (EAACI) statement has addressed issues and recommendations on how to handle allergen immunotherapy (AIT) during the pandemic ${ }^{1}$.

AIT, the only disease modifying therapy that confers a long-term clinical benefit for respiratory, venom and food allergies, has been used as a treatment modality for more than 100 years ${ }^{2-5}$. Subcutaneous immunotherapy (SCIT), the oldest route of administration has disadvantages like necessity of regular follow-ups and applications in the clinic when compared to other routes ${ }^{2,3,6}$. Therefore, it is inevitable that there could be disruptions in SCIT administrations during the COVID-19 pandemic that has deeply affected the health care system.

The ARIA-EAACI statement document recommended prolonging injection intervals during SCIT in patients acutely infected by severe acute respiratory syndrome coronavirus 2 (SARS-CoV-2) like in other respiratory infections. However, by taking necessary precautions, the continuation of SCIT was recommended in asymptomatic patients without suspicious infection and/or possible contact with SARS-CoV-2 positive individuals, 
in patients with negative test results, in those following an adequate quarantine period and finally in those with high serum IgG levels to SARS-CoV2 with non-detectable virus specific IgM levels ${ }^{1}$. This statement is expected to have an important influence in guiding daily clinical practice of SCIT in many countries since treatment disruptions caused by a pandemic is a new field for the physicians and it is important to prevent any negative effects on treatment success. Real-life data on SCIT practices during the pandemic are important to show the implementation and further improvement of such recommendations. In this real-life multicentre study, our aim was to investigate adherence to SCIT and influence of treatment disruptions on short-term clinical outcomes in patients on maintenance phase of SCIT with aeroallergens during the COVID-19 pandemic.

\section{METHODS:}

\section{Study design}

This multi-centre study was prospectively conducted on adult allergic rhinitis (AR) and/or asthmatic patients receiving the maintenance phase of SCIT with aeroallergens in the coordinating centre of the study, the adult immunology and allergy clinic at Istanbul Faculty of Medicine and in three other adult immunology and allergy centres in Istanbul (Yedikule Chest Diseases and Thoracic Surgery Education and Research Hospital, Şişli Hamidiye Etfal Education and Research Hospital, Kartal Dr Lütfi Kırdar Education and Research Hospital).

During the study period of March 15, 2021 and September 15, 2021, patients' routine SCIT injection visits were continued under strict virus transmission prevention measures. All staff members used personal protective equipments during SCIT application visits to ensure standard contact and droplet protection ${ }^{1}$. Wearing a surgical mask was mandatory for all patients. Sufficient time was left between each application and interviews to provide ambient ventilation, necessary preparations and disinfection of materials that might have been contaminated. As recommended, injection visits were not interrupted unless the patient and/or his/her contact persons were infected ${ }^{1}$.

Treatment interruptions and their reasons were collected through telephone interviews at the end of August. In addition, the patients' educational status, professions, transportation options for reaching the hospital, smoking habits, co-morbid diseases, concomitant drug usage and concomitant COVID-19 infection, were all questioned.

The patients were allocated into three groups according to SCIT application periods. The first group consisted of the patients who received SCIT injections in the recommended routine time interval of one month. The patients who missed injection doses that resulted in an interval of $<2$ months and [?]2 months between subsequent injections formed the second and third groups, respectively ${ }^{2}$. Patients in Group 3 were considered as non-adherent whereas patients in Group 1 and Group 2 as adherent according to SCIT adherence studies $^{2}$. The reasons for missing doses were questioned and identified. Patients' demographic features and clinical diagnostic tests were collected from medical chart records. The measures of asthma control test $(\mathrm{ACT})^{7}$, symptom, medication and quality of life (QoL) scores were applied routinely on injection visits every six months before the pandemic and once during the pandemic and were compared among adherent and non-adherent groups.

Before the study, ethical approval from the ethics committee of Istanbul Faculty of Medicine (2020/78367) and authorization from The Ministry of Health for conducting the study (2020-06-04T13_52_49) were obtained. After the clinical data of each patient were filled in medical charts and were ready to be used as study documents, patients' informed consent forms were collected after the telephone interviews in order not to influence the real-life findings of the study.

\section{Patients recruitment}

The patients older than 18 years of age with $\mathrm{AR}$ and/or allergic asthma who were receiving the maintenance phase of SCIT with pollen, house dust mite (HDM), cat or mold allergens during the study period were included in the study. 


\section{The evaluation of symptom, medication and quality of life scores}

Symptom scores with both the total symptom score-6 (TSS-6) and the visual analogue scale (VAS) ${ }^{8,9}$, and QoL with $\mathrm{VAS}^{2,9}$ are applied to all patients before the initiation of immunotherapy and in every six months until the end of the therapy as part of a routine clinical practice at the study centres. The TSS6 was assessed by the sum of six symptoms related to nasal, ocular, ear and/or palate with ratings for each symptom ranging from 0 to 3 with a total possible score from 0 (absence of symptoms) to 18 (very severe $)^{2,9}$. VAS-symptom scores ranged from 'nasal symptoms, not at all bothersome' $(0 \mathrm{~cm})$ to "nasal symptoms, extremely bothersome' $(10 \mathrm{~cm})^{9}$. The QoL scores were measured with VAS which ranged from intolerable bothersome' $(0 \mathrm{~cm})$ to 'not at all bothersome' $(10 \mathrm{~cm})$. The patients were instructed to use rescue medication as a stepwise regiment by stepping it up when symptoms were not sufficiently alleviated. The medication score (MS) from the study by Gelincik et al. was used and defined according to the steps, with a range from 0 to 6 shown in supplementary Table $1^{2}$. MSs in the pre-pandemic period were determined from the data in the medical charts whereas MSs during the pandemic were assessed at the last injection visit.

\section{Statistical Analysis:}

All analyses were performed with the SPSS version 21. Descriptive data were given as percentages and as mean \pm SD or median (IQR 25-75). The comparisons of ACT, VAS-symptom, TSS-6, VAS-QoL and MS between the pre-pandemic and during the pandemic periods were performed with the Wilcoxon signed rank test while the comparisons of ACT, VAS-symptom, TSS-6, VAS-QoL and MS between the groups were performed with the Kruskal Wallis $\mathrm{H}$ test. The scores of ACT, VAS-symptom, VAS-QoL, MS and TSS-6 during the pandemic were compared between the groups in pairs with the Mann Whitney U test. Categorical variables were evaluated using the chi-square test among groups and significant variables were further evaluated using the logistic regression analysis. Spearman correlation test was used to show the correlation between the delay in the application time of the patients and the differences in VAS-symptom, VAS-QoL, TSS-6 and MSs due to the pandemic. The power of correlation was defined as very weak if $\mathrm{r}<0.2$, weak if $\mathrm{r}=0.2-0.4$, moderate if $\mathrm{r}=0.4-0.6$, strong if $\mathrm{r}=0.6-0.8$, very strong if $\mathrm{r}>0.8$. The results were assessed at a significant level of $\mathrm{p}<0.05$ and a $95 \%$ confidence interval (CI).

\section{RESULTS:}

\section{Demographic and clinical features of the study participants}

A total of 327 adult patients were included in the study. The mean age was $35 \pm 11.1$ years and majority of them $(62.4 \%)$ were female. $73.4 \%(\mathrm{n}=240), 26.3 \%(\mathrm{n}=86)$ and $0.3 \%(\mathrm{n}=1)$ of the patients had AR, concomitant AR and allergic asthma, and allergic asthma, respectively. 249 (76.1\%) patients were sensitive to HDM, $96(29.3 \%)$ were sensitive to pollen, $8(2.4 \%)$ were sensitive to cat and $1(0.3 \%)$ was sensitive to mold. The median duration of SCIT was 23 months (IQR 25-75: 10-36 months). During the COVID-19 pandemic, immunotherapy was administered to 151 (46.1\%) patients (Group 1) at recommended intervals, 72 (22\%) patients at extended intervals of less than 2 months (Group 2) and 104 (31.8\%) patients at extended intervals of at least 2 months (Group 3). The demographic and clinical features of the patients are shown in detail in Table 1.

\section{Adherence rates and reasons for extending SCIT administration intervals}

$104(31.8 \%)$ patients (Group 3) were considered as non-adherent whereas 72 (22\%) patients (Group 2) who extended injection intervals for less than 2 months and 151 (46\%) patients (Group 1) who received injections on routine injection visits were adherent.

The reasons for extending the SCIT administration intervals during the pandemic in Group $2(\mathrm{n}=72)$ in decreasing significance order were as follows; staying at home due to precautionary reasons for 33 patients (45.8\%), unwilling to go to the hospital for 18 patients (25\%), transportation problems for 6 patients (8.3\%), delay in the import of the vaccine for 4 patients (5.6\%), having acute COVID-19 for 4 patients (5.6\%), the thought that allergy clinics were closed during the pandemic for 4 patients $(5.6 \%)$ and personal reasons unrelated to the pandemic for 3 patients $(4.2 \%)$. 
In Group 3, the reasons of non-adherence were; staying at home due to precautionary reasons for 48 patients (46.2\%), unwilling to go to the hospital for 12 patients (11.5\%), transportation problems for 17 patients $(16.4 \%)$, delay in the import of the vaccine for 16 patients $(15.4 \%)$, having acute COVID-19 for 5 patients (4.8\%), having a health problem other than COVID-19 for 2 patients (1.9\%), the thought that allergy clinics were closed during the pandemic for 2 patients (1.9\%) and personal reasons unrelated to the pandemic for 2 patients $(1.9 \%)$, respectively.

Univariate analysis revealed that AIT with HDM and public transport usage were higher in the non-adherent group than the adherent group ( $\mathrm{p}=0.003, \mathrm{p}=0.010$, respectively) whereas the patients receiving pollen SCIT with or without another concomitant allergen $(\mathrm{n}=96)$ were more adherent $(\mathrm{p}=0.003)$ (Table 1$)$. In the logistic regression analysis, AIT with HDM and public transport usage were significantly higher among non-adherent patients (patients in Group 3) than adherent patients (patients in Group 1 and Group 2) ( $\mathrm{p}=0.009, \mathrm{p}=0.026$, respectively) (Table 2).

\section{Comparison of AIT effectiveness and quality of life between groups}

Before the pandemic, the median TSS-6, VAS-symptom, MS and VAS-QoL scores were similar in all groups ( $>0.05$ for each comparison). During the pandemic, the median TSS-6 and VAS-symptom scores were the highest in Group 3 compared to other groups $(\mathrm{p}<0.001$ for each comparison) and these values were similar between Group 1 and Group 2 ( $\mathrm{p}>0.05, \mathrm{p}>0.05$, respectively). The median MSs were similar in all groups during the pandemic $(\mathrm{p}>0.05)$. Median VAS-QoL scores were the lowest in Group 3 compared to others $(\mathrm{p}<0.001$ for each comparison) and were lower in Group 2 than Group $1(\mathrm{p}=0.043)$ (Figure 1).

When the adherent and the non-adherent patients were compared, the median TSS-6, VAS-symptom, MS and VAS-QoL scores were similar before the pandemic ( $>0.05$ for each comparison). During the pandemic, the median TSS-6 and VAS-symptom scores were higher and the median VAS-QoL score was lower in the non-adherent patients than the adherent patients ( $\mathrm{p}<0.001$ for each comparison). However, the median MS was similar in both groups during the pandemic $(\mathrm{p}>0.05)$ (Figure 2$)$.

Since the study period corresponds to the pollination period of common pollen allergens in our geographic region, the patients who received and those who did not receive pollen immunotherapy were compared in terms of short-term clinical outcomes of AIT. Changes in MS, VAS-symptom, VAS-QoL and TSS-6 scores between the pandemic and the pre-pandemic periods were similar among these patients $(\mathrm{p}>0.05$ for each comparison).

\section{Comparison of AIT effectiveness and quality of life within groups}

Median TSS-6, VAS-symptom, MS and VAS-QoL scores calculated before and during the pandemic were similar in Group 1 ( $\mathrm{p}>0.05$ for each score). In Group 2, median values of VAS-symptom were higher during the pandemic than the pre-pandemic period while TSS- 6 and MS were similar in both periods $(\mathrm{p}=0.002$, $\mathrm{p}>0.05, \mathrm{p}>0.05$ ). Also, median values of VAS-QoL decreased during the pandemic compared to pre-pandemic period in the same group $(\mathrm{p}<0.001)$ (Figure 1$)$.

In adherent patients, VAS-symptom increased and VAS-QoL decreased during the pandemic compared to the pre-pandemic period $(\mathrm{p}=0.013, \mathrm{p}<0.001$, respectively) and the median values of TSS- 6 and MS were similar in both periods in adherent patients ( $\mathrm{p}>0.05$ for each comparison). In non-adherent patients, median values of TSS-6, VAS-symptom and MSs were higher and median value of VAS-QoL was lower during the pandemic than the pre-pandemic period ( $\mathrm{p}<0.001, \mathrm{p}<0.001, \mathrm{p}=0.005, \mathrm{p}<0.001$, respectively) (Figure 2).

\section{Evaluation of patients with concomitant asthma}

Comparison of ACT scores between and within the groups during the pandemic and pre-pandemic periods were similar ( $\mathrm{p}>0.05$ for each comparison).

Correlation analysis between the delay in SCIT injections and changes in symptom, medication and quality of life scores in pre-pandemic and pandemic periods 
The differences in VAS-symptom, VAS-QoL and TSS-6 scores between the pre-pandemic and during the pandemic periods were moderately correlated with the increase in the interval time of SCIT application $\mathrm{n}(\mathrm{r}=0.509, \mathrm{p}<0.001 ; \mathrm{r}=0.516, \mathrm{p}<0.001 ; \mathrm{r}=0.521, \mathrm{p}<0.001$; respectively $)$. The difference in MSs between pre-pandemic and during the pandemic periods showed a very weak correlation $(\mathrm{r}=0.188, \mathrm{p}<0.001)$ (Figure $3)$.

\section{AIT effectiveness and quality of life in patients diagnosed with COVID-19 infection during the study period}

During the study period, 12 patients were diagnosed with COVID-19. The mean age of the patients was $37.5 \pm 11.5$ and $7(58.3 \%)$ of them were female. 11 (91.7\%) patients had AR and $1(8.3 \%)$ had concomitant allergic asthma. In 9 patients (75\%), AIT was for HDMs and in 3 patients (25\%), it was for pollens.

9 out of the 12 patients missed SCIT administration due to having COVID-19 infection whereas the remaining 3 patients had SCIT injections on time after completing the quarantine period. While 11 patients had mild symptoms, 1 patient had to stay in hospital due to severe COVID-19 disease.

TSS-6, VAS-symptom and MSs of the patients $(\mathrm{n}=3)$ who had administration on time were similar during pre-pandemic and the pandemic periods. 2 out of the 3 patients had similar VAS-QoL scores during the pre-pandemic and the pandemic periods whereas the pre-pandemic VAS-QoL score was 10 and pandemic score was 9 in the third patient. The TSS-6, VAS-symptom, VAS-QoL and MS median (IQR 25-75) scores during the pre-pandemic period in the patients $(\mathrm{n}=9)$ who missed administration were $3(1-4), 3(1-5.5), 8$ (7.5-9), 0 (0-1), respectively and during the pandemic, they were 5 (2.5-14.5), 7 (3-9.5), 7 (2.5-7.5), 1 (0-2), respectively.

\section{DISCUSSION}

Our study is the first multicentre study which has evaluated adherence to SCIT with aeroallergens during the COVID-19 pandemic and its influence on the short-term clinical outcomes in real-life. We observed that in half of the patients $(53.8 \%)$, SCIT injections were delayed and one third (31.8\%) of the patients were non-adherent during COVID-19 pandemic. Delays in SCIT administration have led to deterioration in the AIT effectiveness and QoL, and the deterioration was even greater in the non-adherent patients.

Adherence to long-term treatments in chronic diseases is very crucial for the success of the treatment ${ }^{3}$. The definition of adherence to SCIT differs in studies, however we referred to a previous study which was conducted by our group and considered the cut-off time interval for being non-adherent as 2 months accordingly $^{2}$. Moreover, we also determined the clinical results of shorter delays of less than 2 months in injection intervals in a separate patient group in order to strengthen our findings. By this way, we have captured all significant clinical consequences of delays in injection intervals. Since our study is the first adherence study during the pandemic, we could only compare our results with previous SCIT adherence studies published before the pandemic. In the majority of the adherence studies on SCIT, the adherence rates are less than $70 \%^{2,10-13}$. Furthermore, they are even lower according to real-life data ${ }^{2,14,15}$. In our study, $68.2 \%$ of the patients were adherent to SCIT during the pandemic. We can speculate that this acceptable adherence rate in our study may be due to continuous treatment with appropriate preventive measures applied despite the negative effects of the pandemic and the close cooperation that had been established between the allergists and the patients in the study centres before the pandemic.

As a main finding of our study, delay in SCIT administrations led to deterioration in AR symptoms and QoL of our patients. Delays of less than 2 months between subsequent SCIT injections worsened QoL and symptom scores in Group 2 patients whereas in the non-adherent group MSs were additionally disrupted. Therefore, we suggest that it is important to continue SCIT injections without giving intervals more than recommended in order not to affect the short-term effectiveness of AIT even during a pandemic ${ }^{16}$. Prolonged intervals in the SCIT applications is also an important issue to make appropriate dose adjustments to restart SCIT after gaps in the administration ${ }^{17}$. In our study, after interruptions of maintenance doses especially in non-adherent patients, dose adjustments starting with frequent lower dose injections caused frequent hospital 
visits which can probably bring additional burden on the healthcare system.

The two main reasons of non-adherence to SCIT in our study were using public transport for reaching the hospital and receiving SCIT with HDMs. In accordance with our findings, a study from the USA reported that one of the reasons of premature cessation of SCIT was the inconvenience of travel ${ }^{18}$. It is very obvious that patients using public transportation during a pandemic may discontinue SCIT injection visits in order to reduce the risk of being infected. In a study, adherence to pollen SCIT was higher than the SCITs with other allergens ${ }^{14}$ while in other studies no relationship between allergen type and adherence was observed ${ }^{2,18}$. Since our study was conducted in the pollen season ${ }^{19,20}$, the adherence in patients receiving pollen SCIT was better than those receiving SCIT with HDMs. We assume that these patients were worried about having severe AR and/or asthmatic symptoms during the pollen season corresponding to the pandemic therefore received more regular SCIT injections. However, we did not observe any significant changes in the scores of the patients who received pollen or HDM SCIT before and during the pandemic. Moreover, VAS-symptom, VAS-QoL, TSS-6 and MS did not deteriorate during pollen season for most of the pollen SCIT patients who received the treatment regularly.

Among demographic factors; age, gender, occupation and socioeconomic status were related to non-adherence to SCIT in recent studies $2,14,18,21,22$. However, we did not observe any association between these factors and adherence. This difference might be due to the fact that the COVID-19 pandemic has similarly affected people with different demographic characteristics. Furthermore, having diagnosis of AR or AR with asthma was not related to adherence to SCIT administrations similar to some adherence studies ${ }^{2,12,23}$.

Our study focused on the effects of patient behaviours on SCIT application during the pandemic since the physician behaviours were not significantly different from the pre-pandemic period. However, the delay in SCIT applications may also occur due to the clinical practice preferences of the physicians. In a current international EAACI survey study investigating the AIT practice behaviours of physicians during the pandemic, it has been shown that $41 \%$ of the participants extended the application period and $13 \%$ paused it during the pandemic ${ }^{24}$. We believe our study is important in showing the short-term clinical consequences in case of delays between SCIT injections depending on patient behaviours and it also supports the recent AIT recommendations of EAACI ${ }^{1}$.

As a limitation of our study, we have compared our findings with results of previous adherence studies conducted during normal life while interpreting the clinical results of treatment disruptions related to the pandemic. However, social restrictions affecting different aspects of daily life and mental changes caused by the pandemic may generate its own dynamics which may limit the comparison of study results with previous studies. In addition, whereas adherence studies usually comprise of long periods of AIT, our study has presented adherence to SCIT for a short-term period of 6 months. However, we plan to further evaluate the same patient groups for longer periods to show long-term effectiveness of SCIT and adherence rates in relation to the pandemic. Finally, our results are convincing, regarding the high number of patients, similar median duration of maintenance phases of SCIT before the study between the groups and similar initial symptom, medication and quality of life scores, although the patient groups were not homogenous in terms of allergens applied during the SCIT injections, sensitivity and the presence of asthma.

In conclusion, in the current study, the negative effects of COVID-19 pandemic on adherence to SCIT administrations and short-term clinical efficacy have been demonstrated in real-life. We believe that it is important to continue SCIT administrations by providing the necessary precautions in allergy clinics during a pandemic in order to maintain the clinical efficacy of the treatment.

\section{Acknowledgements}

Dr Yeğit, Dr Demir, Dr Ünal, Dr Olgac, Dr Terzioğlu, Dr Eyice, Dr Tüzer, Dr Ayhan, Dr Çolakoğlu, Dr Büyüköztürk, Dr Gelincik have nothing to disclose.

\section{Conflicts of interest}

Authors state that there is no conflict of interest about this study. 


\section{REFERENCES:}

1. Klimek L, Jutel M, Akdis C, et al. Handling of allergen immunotherapy in the COVID-19 pandemic: An ARIA-EAACI statement. Allergy.2020;75(7):1546-1554.

2. Gelincik A, Demir S, Olgac M, et al. High adherence to subcutaneous immunotherapy in a real-life study from a large tertiary medical center.Allergy \&3 Asthma Proceedings. 2017;38(6):78-84.

3. Reisacher WR, Visaya JM. Patient adherence to allergy immunotherapy.Current Opinion in Otolaryngology $\& 3$ Head and Neck Surgery.2013;21(3):256-262.

4. Bousquet J, Lockey R, Malling H-J. Allergen immunotherapy: therapeutic vaccines for allergic diseases A WHO position paper.Journal of Allergy and Clinical Immunology. 1998;102(4):558-562.

5. Durham SR, Leung DY. One hundred years of allergen immunotherapy: time to ring the changes. Journal of Allergy and Clinical Immunology. 2011;127(1):3-7.

6. Nelson HS. Advances in upper airway diseases and allergen immunotherapy. Journal of allergy and clinical immunology.2003;111(3):793-798.

7. Schatz M, Sorkness CA, Li JT, et al. Asthma Control Test: reliability, validity, and responsiveness in patients not previously followed by asthma specialists. Journal of Allergy and Clinical Immunology. 2006;117(3):549-556.

8. Bousquet P, Combescure C, Neukirch F, et al. Visual analog scales can assess the severity of rhinitis graded according to ARIA guidelines. Allergy. 2007;62(4):367-372.

9. Demoly P, Bousquet P, Mesbah K, Bousquet J, Devillier P. Visual analogue scale in patients treated for allergic rhinitis: an observational prospective study in primary care: asthma and rhinitis. Clinical $\mathscr{E}$ Experimental Allergy. 2013;43(8):881-888.

10. Donahue JG, Greineder DK, Connor-Lacke L, Canning CF, Platt R. Utilization and cost of immunotherapy for allergic asthma and rhinitis.Annals of Allergy, Asthma \&3 Immunology. 1999;82(4):339-347.

11. Hankin CS, Cox L, Lang D, et al. Allergy immunotherapy among Medicaid-enrolled children with allergic rhinitis: patterns of care, resource use, and costs. Journal of allergy and clinical immunology. 2008;121(1):227-232.

12. More DR, Hagan LL. Factors affecting compliance with allergen immunotherapy at a military medical center. Annals of Allergy, Asthma 83 Immunology. 2002;88(4):391-394.

13. Pajno GB, Vita D, Caminiti L, et al. Children's compliance with allergen immunotherapy according to administration routes. Journal of allergy and clinical immunology. 2005;116(6):1380-1381.

14. Kiel MA, Roder E, van Wijk RG, Al MJ, Hop WC, Rutten-van Molken MP. Real-life compliance and persistence among users of subcutaneous and sublingual allergen immunotherapy. Journal of Allergy and Clinical Immunology. 2013;132(2):353-360.

15. Egert-Schmidt A-M, Kolbe J-M, Mussler S, Thum-Oltmer S. Patients' compliance with different administration routes for allergen immunotherapy in Germany. Patient preference and adherence.2014;8:1475-1481.

16. Roberts G, Pfaar O, Akdis C, et al. EAACI guidelines on allergen immunotherapy: allergic rhinoconjunctivitis. Allergy.2018;73(4):765-798.

17. Larenas-Linnemann DE, Epstein T, Ponda P, Bernstein D, Williams P, Creticos P. Gaps in allergen immunotherapy administration and subcutaneous allergen immunotherapy dose adjustment schedules: Need for prospective data. Annals of Allergy, Asthma \& Immunology.2020;125(5): 505-506.

18. Vaswani R, Garg A, Parikh L, Vaswani S. Non-adherence to subcutaneous allergen immunotherapy: inadequate health insurance coverage is the leading cause. Annals of Allergy, Asthma 86 Immunology. 
2015;115(3):241-243.

19. Celenk S, Bicakci A, Tamay Z, et al. Airborne pollen in European and Asian parts of Istanbul. Environmental monitoring and assessment.2010;164(1-4):391-402.

20. Hoffmann TM, Acar Şahin A, Aggelidis X, et al. "Whole" vs."fragmented" approach to EAACI pollen season definitions: A multicenter study in six Southern European cities. Allergy.2020;75(7):1659-1671.

21. Lower T, Henry J, Mandik L, Janosky J, Friday Jr G. Compliance with allergen immunotherapy. Annals of allergy. 1993;70(6):480-482.

22. Rhodes BJ. Patient dropouts before completion of optimal dose, multiple allergen immunotherapy. Annals of Allergy, Asthma \& Immunology. 1999;82(3):281-286.

23. Tinkelman D, Smith F, Cole 3rd W, Silk HJ. Compliance with an allergen immunotherapy regime. Annals of allergy, asthma \& immunology: official publication of the American College of Allergy, Asthma, ES Immunology. 1995;74(3):241-246.

24. Pfaar O AI, Bonini M, Annaruth BH, et al. COVID-19 pandemic and allergen immunotherapy - an EAACI survey. Allergy. 2021; Manuscript submitted for publication.

Supplementary Table 1: Medication scores ${ }^{2}$

Medication

No rescue medication

Nasal / ocular / oral antihistamine or bronchodilator

Nasal corticosteroid, inhaled corticosteroid

Leukotriene receptor antagonist

Leukotriene receptor antagonist and nasal corticosteroid

Leukotriene receptor antagonist and antihistamine (nasal/ocular/oral) with or without corticosteroid (nasal/inhaled)

Oral corticosteroid

Table 1: Clinical and demographic data of the patients

\begin{tabular}{|c|c|c|c|c|c|c|c|c|}
\hline & & $\begin{array}{l}\text { Group } 1 \\
(n=151)\end{array}$ & $\begin{array}{l}\text { Group } 2 \\
(n=72)\end{array}$ & $\begin{array}{l}\text { Patients } \\
\text { Group } 2 \\
(n=72)\end{array}$ & $\begin{array}{l}\text { Patients } \\
\text { Group } \\
1+2 \text { (Ad- } \\
\text { herent) } \\
(\mathbf{n}=223)\end{array}$ & $\begin{array}{l}\text { Patients } \\
\text { Group } 3 \\
\text { (Non- } \\
\text { adherent) } \\
(n=104)\end{array}$ & $\begin{array}{l}\text { Patients } \\
\text { Group } 3 \\
\text { (Non- } \\
\text { adherent) } \\
(n=104)\end{array}$ & $\mathbf{P}^{*}$ \\
\hline $\begin{array}{l}\text { Age, } \\
\text { mean }\end{array}$ & $\begin{array}{l}\text { Age, } \\
\text { mean }\end{array}$ & $36.5 \pm 11.3$ & $36.5 \pm 11.3$ & $32.9 \pm 10.7$ & $35.4 \pm 11.2$ & $35.4 \pm 11.2$ & $34.3 \pm 10.8$ & NS \\
\hline Sex, n (\%) & Sex, n (\%) & $90(59.6)$ & $90(59.6)$ & $45(62.5)$ & $135(60.5)$ & $135(60.5)$ & $69(66.3)$ & NS \\
\hline Women & Women & $61(40.4)$ & $61(40.4)$ & $27(37.5)$ & $88(39.5)$ & $88(39.5)$ & $35(33.7)$ & \\
\hline
\end{tabular}




\begin{tabular}{|c|c|c|c|c|c|c|c|c|}
\hline Diagnosis & Diagnosis & 111 & 111 & 56 & 167 & 167 & 73 & NS NS \\
\hline of respi- & of respi- & (73.5) 0 & $(73.5) 0$ & (77.8) 0 & $(74.9) 0$ & (74.9) 0 & $(70.2) 1$ & $\mathrm{NS}$ \\
\hline ratory & ratory & (0) 40 & (0) 40 & (0) 16 & (0) 56 & (0) 56 & (1) 30 & \\
\hline $\begin{array}{l}\text { diseases, } \\
\mathrm{n}(\%)\end{array}$ & $\begin{array}{l}\text { diseases, } \\
\mathrm{n}(\%)\end{array}$ & $(26.5)$ & $(26.5)$ & $(22.2)$ & $(25.1)$ & $(25.1)$ & $(28.8)$ & \\
\hline Allergic & Allergic & & & & & & & \\
\hline rhinitis & rhinitis & & & & & & & \\
\hline Allergic & Allergic & & & & & & & \\
\hline asthma & asthma & & & & & & & \\
\hline Allergic & Allergic & & & & & & & \\
\hline rhinitis & rhinitis & & & & & & & \\
\hline and & and & & & & & & & \\
\hline asthma & asthma & & & & & & & \\
\hline
\end{tabular}




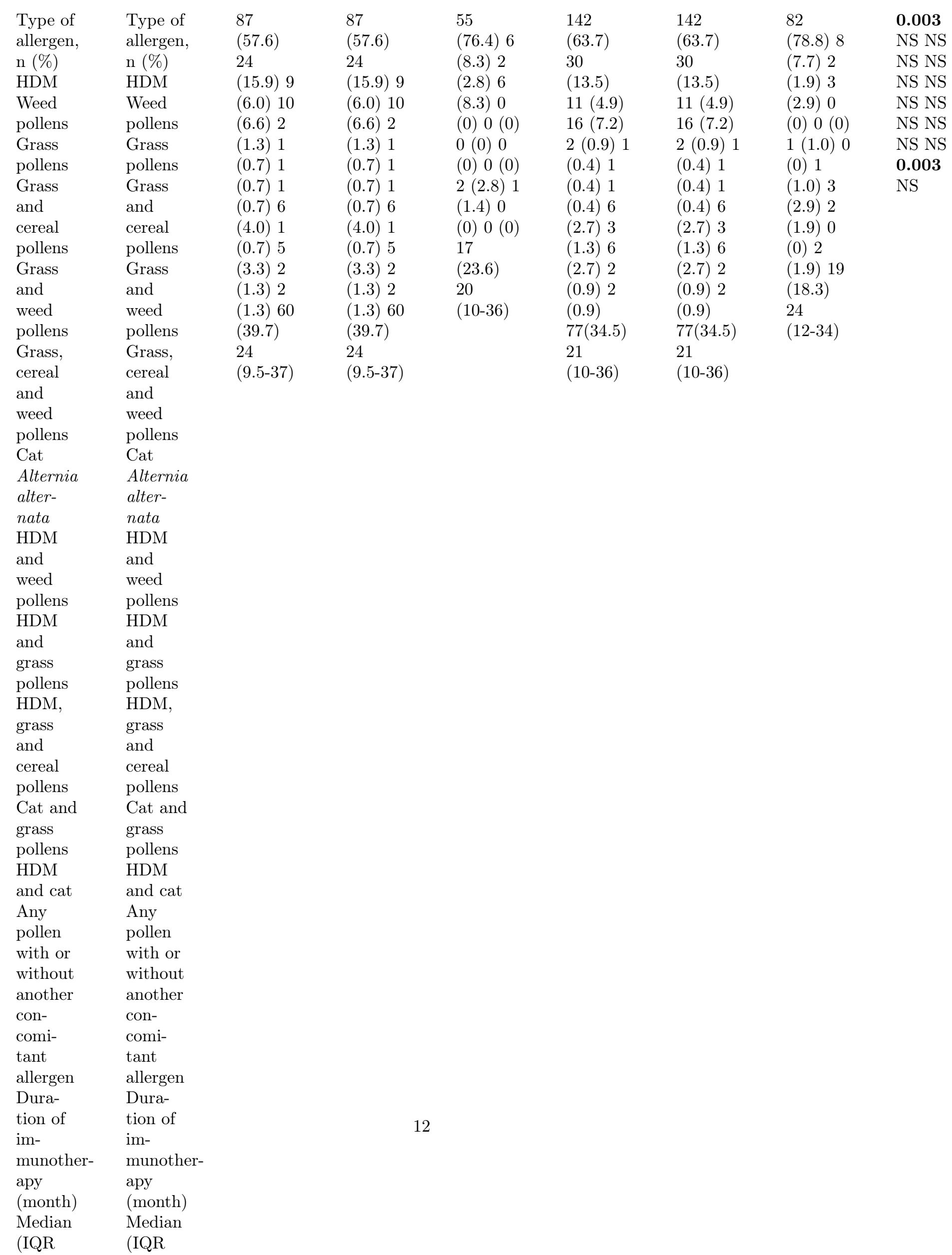




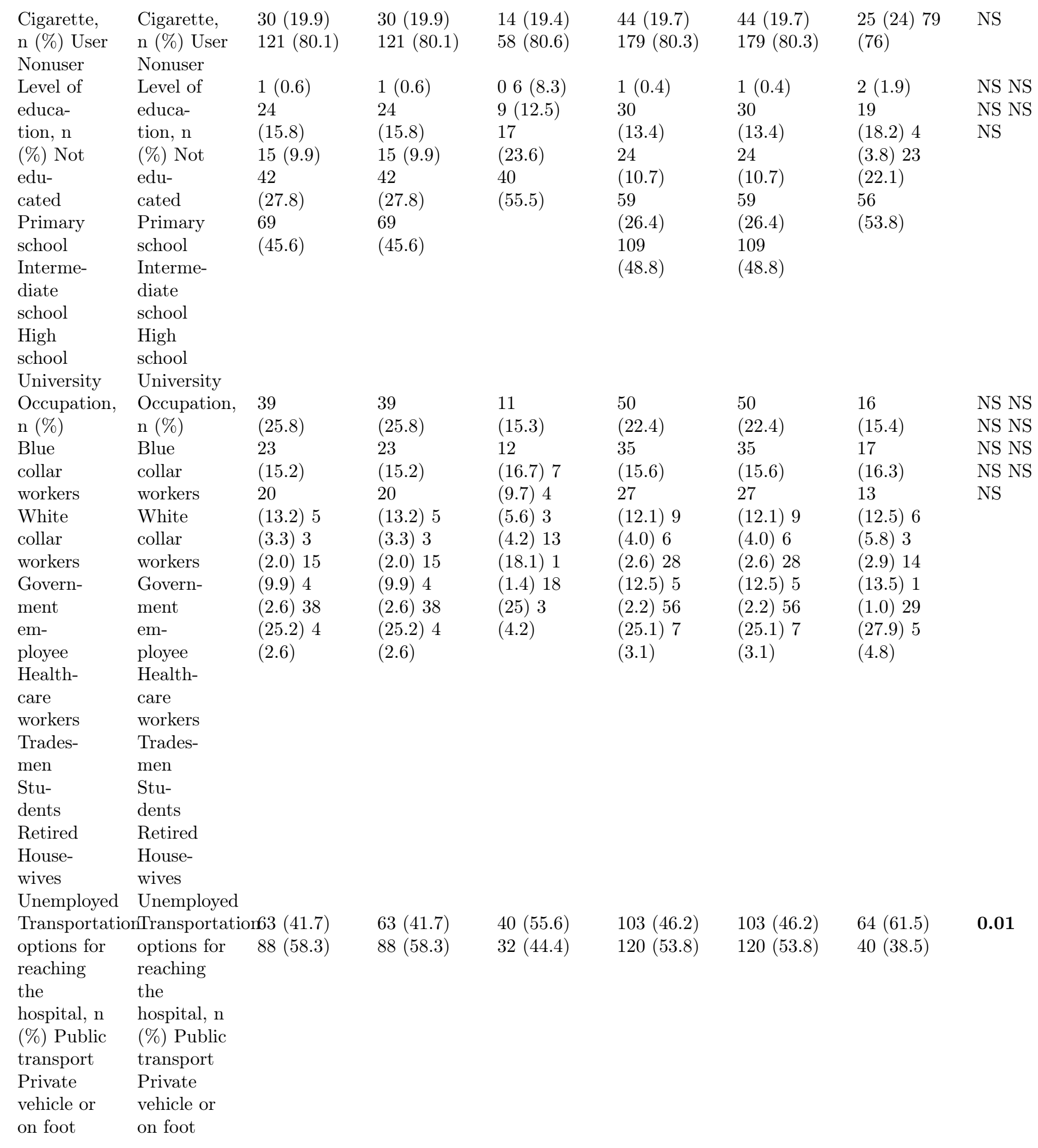




\begin{tabular}{|c|c|c|c|c|c|c|c|}
\hline Group 1 & Group 1 & Group 1 & Group 1 & Group 1 & Group 1 & Group 1 & Group \\
\hline$=$ & $=$ & $=$ & $=$ & $=$ & $=$ & $=$ & $=$ \\
\hline routine & routine & routine & routine & routine & routine & routine & routine \\
\hline $\begin{array}{l}\text { inter- } \\
\text { vals; }\end{array}$ & $\begin{array}{l}\text { inter- } \\
\text { vals; }\end{array}$ & $\begin{array}{l}\text { inter- } \\
\text { vals; }\end{array}$ & $\begin{array}{l}\text { inter- } \\
\text { vals; }\end{array}$ & $\begin{array}{l}\text { inter- } \\
\text { vals; }\end{array}$ & $\begin{array}{l}\text { inter- } \\
\text { vals; }\end{array}$ & $\begin{array}{l}\text { inter- } \\
\text { vals; }\end{array}$ & $\begin{array}{l}\text { inter- } \\
\text { vals; }\end{array}$ \\
\hline Group 2 & Group 2 & Group 2 & Group 2 & Group 2 & Group 2 & Group 2 & Group \\
\hline $\begin{array}{l}=\text { ex- } \\
\text { tended }\end{array}$ & $\begin{array}{l}=\text { ex- } \\
\text { tended }\end{array}$ & $\begin{array}{l}=\text { ex- } \\
\text { tended }\end{array}$ & $\begin{array}{l}=\mathrm{ex}- \\
\text { tended }\end{array}$ & $\begin{array}{l}=\text { ex- } \\
\text { tended }\end{array}$ & $\begin{array}{l}=\text { ex- } \\
\text { tended }\end{array}$ & $\begin{array}{l}=\mathrm{ex}- \\
\text { tended }\end{array}$ & $\begin{array}{l}=\mathrm{ex}- \\
\text { tended }\end{array}$ \\
\hline intervals & intervals & intervals & intervals & intervals & intervals & intervals & interv \\
\hline$(<2$ & $(<2$ & $(<2$ & $(<2$ & $(<2$ & $(<2$ & $(<2$ & $(<2$ \\
\hline months); & months); & months); & months); & months); & months); & months); & months \\
\hline Group 3 & Group 3 & Group 3 & Group 3 & Group 3 & Group 3 & Group 3 & Group \\
\hline $\begin{array}{l}=\text { ex- } \\
\text { tended }\end{array}$ & $\begin{array}{l}=\text { ex- } \\
\text { tended }\end{array}$ & $\begin{array}{l}=\text { ex- } \\
\text { tended }\end{array}$ & $\begin{array}{l}=\text { ex- } \\
\text { tended }\end{array}$ & $\begin{array}{l}=\text { ex- } \\
\text { tended }\end{array}$ & $\begin{array}{l}=\text { ex- } \\
\text { tended }\end{array}$ & $\begin{array}{l}=\text { ex- } \\
\text { tended }\end{array}$ & $\begin{array}{l}=\mathrm{ex}- \\
\text { tended }\end{array}$ \\
\hline intervals & intervals & intervals & intervals & intervals & intervals & intervals & interv \\
\hline$([?] 2$ & $([?] 2$ & $([?] 2$ & $([?] 2$ & $([?] 2$ & $([?] 2$ & $([?] 2$ & $([?] 2$ \\
\hline months); & months); & months); & months); & months); & months); & months); & months \\
\hline $\mathrm{NS}=$ & $\mathrm{NS}=$ & $\mathrm{NS}=$ & $\mathrm{NS}=$ & $\mathrm{NS}=$ & $\mathrm{NS}=$ & $\mathrm{NS}=$ & $\mathrm{NS}=$ \\
\hline non- & non- & non- & non- & non- & non- & non- & non- \\
\hline $\begin{array}{l}\text { significant; } \\
\mathrm{HDM}=\end{array}$ & $\begin{array}{l}\text { significant; } \\
\mathrm{HDM}=\end{array}$ & $\begin{array}{l}\text { significant; } \\
\mathrm{HDM}=\end{array}$ & $\begin{array}{l}\text { significant; } \\
\mathrm{HDM}=\end{array}$ & $\begin{array}{l}\text { significant; } \\
\mathrm{HDM}=\end{array}$ & $\begin{array}{l}\text { significant; } \\
\mathrm{HDM}=\end{array}$ & significant; & significa \\
\hline house & house & house & house & house & house & house & \\
\hline dust & dust & dust & dust & dust & dust & dust & dust \\
\hline mite $*$ & mite ${ }^{*}$ & mite ${ }^{*}$ & mite $*$ & mite $*$ & mite ${ }^{*}$ & mite $*$ & mite $*$ \\
\hline The & The & The & The & The & The & The & The \\
\hline $\mathrm{p}$-value & p-value & p-value & $\mathrm{p}$-value & p-value & p-value & p-value & $\mathrm{p}$-value \\
\hline $\begin{array}{l}\text { was cal- } \\
\text { culated }\end{array}$ & $\begin{array}{l}\text { was cal- } \\
\text { culated }\end{array}$ & $\begin{array}{l}\text { was cal- } \\
\text { culated }\end{array}$ & $\begin{array}{l}\text { was cal- } \\
\text { culated }\end{array}$ & $\begin{array}{l}\text { was cal- } \\
\text { culated }\end{array}$ & $\begin{array}{l}\text { was cal- } \\
\text { culated }\end{array}$ & $\begin{array}{l}\text { was cal- } \\
\text { culated }\end{array}$ & was cal \\
\hline between & between & between & between & between & between & between & we \\
\hline adher- & adher- & adher- & adher- & adher- & adher- & adher- & adher- \\
\hline ent and & ent and & ent and & ent and & ent and & ent and & ent and & \\
\hline $\begin{array}{l}\text { non- } \\
\text { adherent } \\
\text { groups }\end{array}$ & $\begin{array}{l}\text { non- } \\
\text { adherent } \\
\text { groups }\end{array}$ & $\begin{array}{l}\text { non- } \\
\text { adherent } \\
\text { groups }\end{array}$ & $\begin{array}{l}\text { non- } \\
\text { adherent } \\
\text { groups }\end{array}$ & $\begin{array}{l}\text { non- } \\
\text { adherent } \\
\text { groups }\end{array}$ & $\begin{array}{l}\text { non- } \\
\text { adherent } \\
\text { groups }\end{array}$ & $\begin{array}{l}\text { non- } \\
\text { adherent } \\
\text { groups }\end{array}$ & $\begin{array}{l}\text { non- } \\
\text { adherer } \\
\text { groups }\end{array}$ \\
\hline
\end{tabular}

Table 2: Logistic regression analysis of the factors associated with being non-adherent

\begin{tabular}{lllll}
\hline Variable & P value & Odds ratio & $\mathbf{9 5} \%$ confidence interval & 95 \% confidence interval \\
Type of allergen: HDM & 0.009 & 2.107 & 1.207 & 3.678 \\
Public transport usage & 0.026 & 1.731 & 1.069 & 2.803 \\
\hline
\end{tabular}




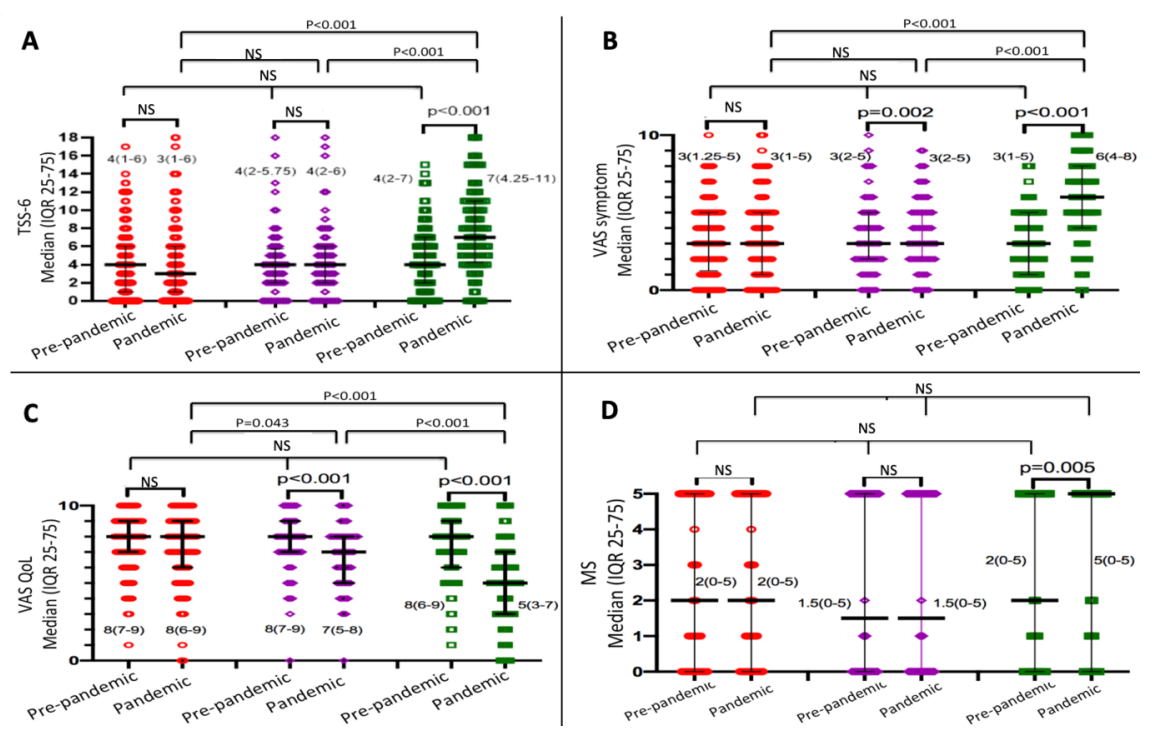

Figure 1: Changes in TSS-6 (A), VAS symptom (B), VAS QoL (C) and MS (D) according to the immunotherapy application interval during COVID-19 pandemic.

NS = non-significant; A = TSS-6; $\mathrm{B}=$ VAS symptom; C = VAS QoL; $\mathbf{D}=$ MS

Red $=$ Group 1; Purple $=$ Group 2; Green $=$ Group 3

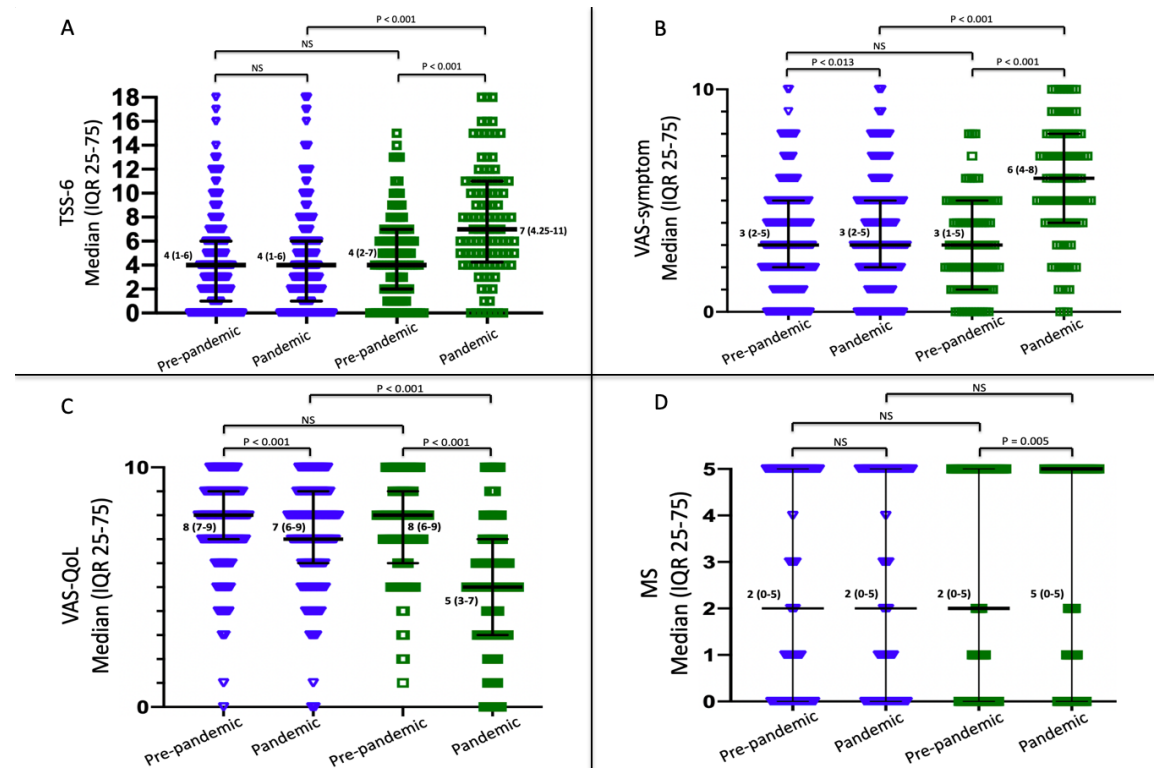

Figure 2: Changes in TSS-6 (A), VAS symptom (B), VAS QoL (C) and MS (D) according to the immunotherapy application interval during COVID-19 pandemic for adherent (Group $1+$ Group 2) and nonadherent patients (Group 3)

NS = non-significant; A $=$ TSS-6; $\mathbf{B}=$ VAS symptom; C = VAS QoL; $\mathbf{D}=$ MS

Blue = adherent; Green: non-adherent 


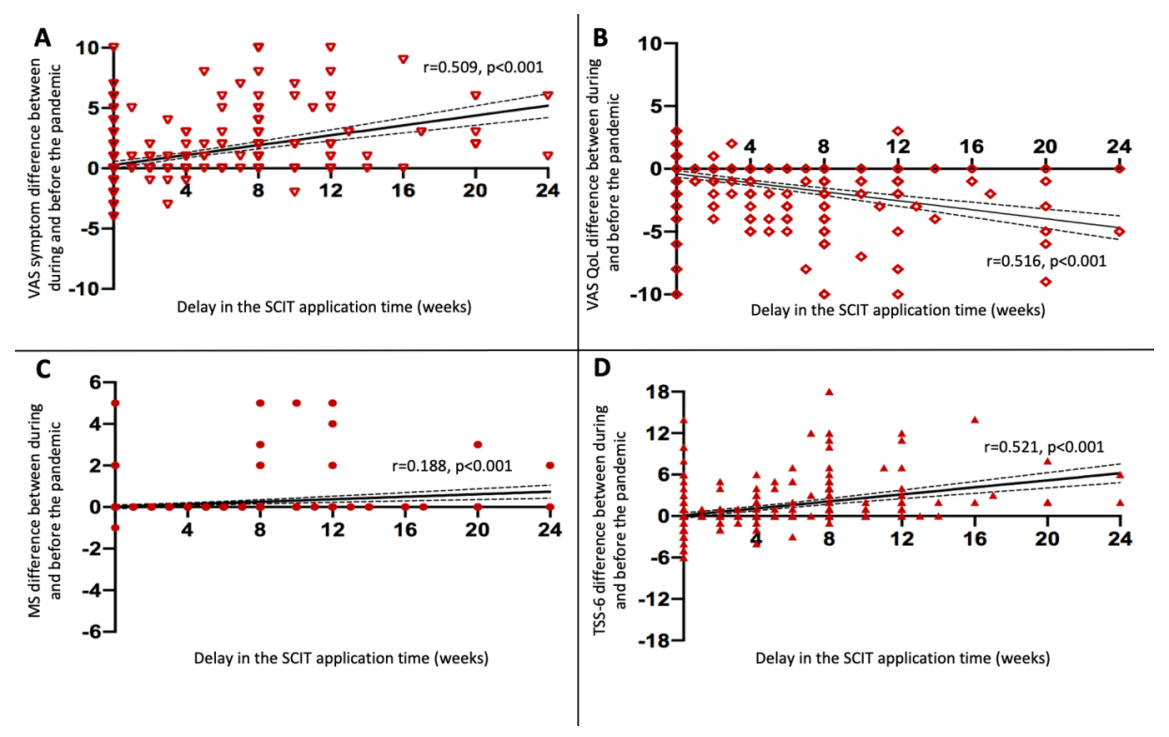

Figure 3: The correlation between delay in the SCIT application and changes of VAS symptom, VAS QoL, MS and TSS-6.

A $=$ VAS symptom, $\mathbf{B}=$ VAS QoL, $\mathbf{C}=$ MS, D $=$ TSS-6

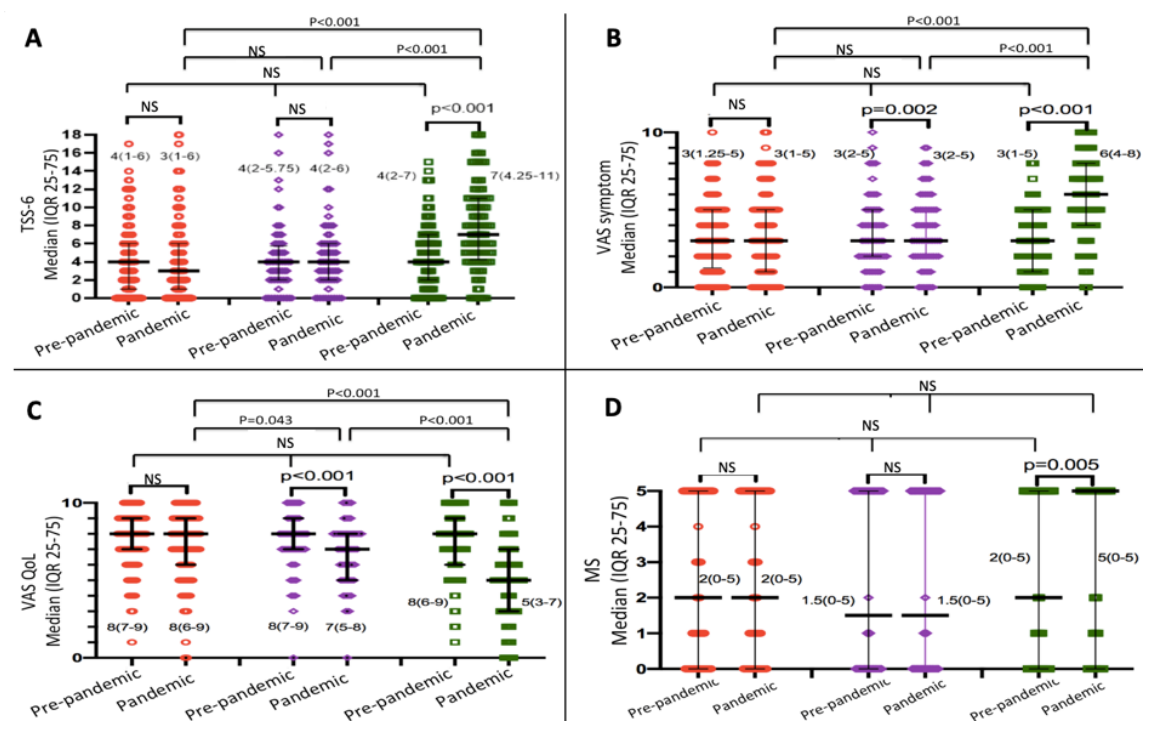



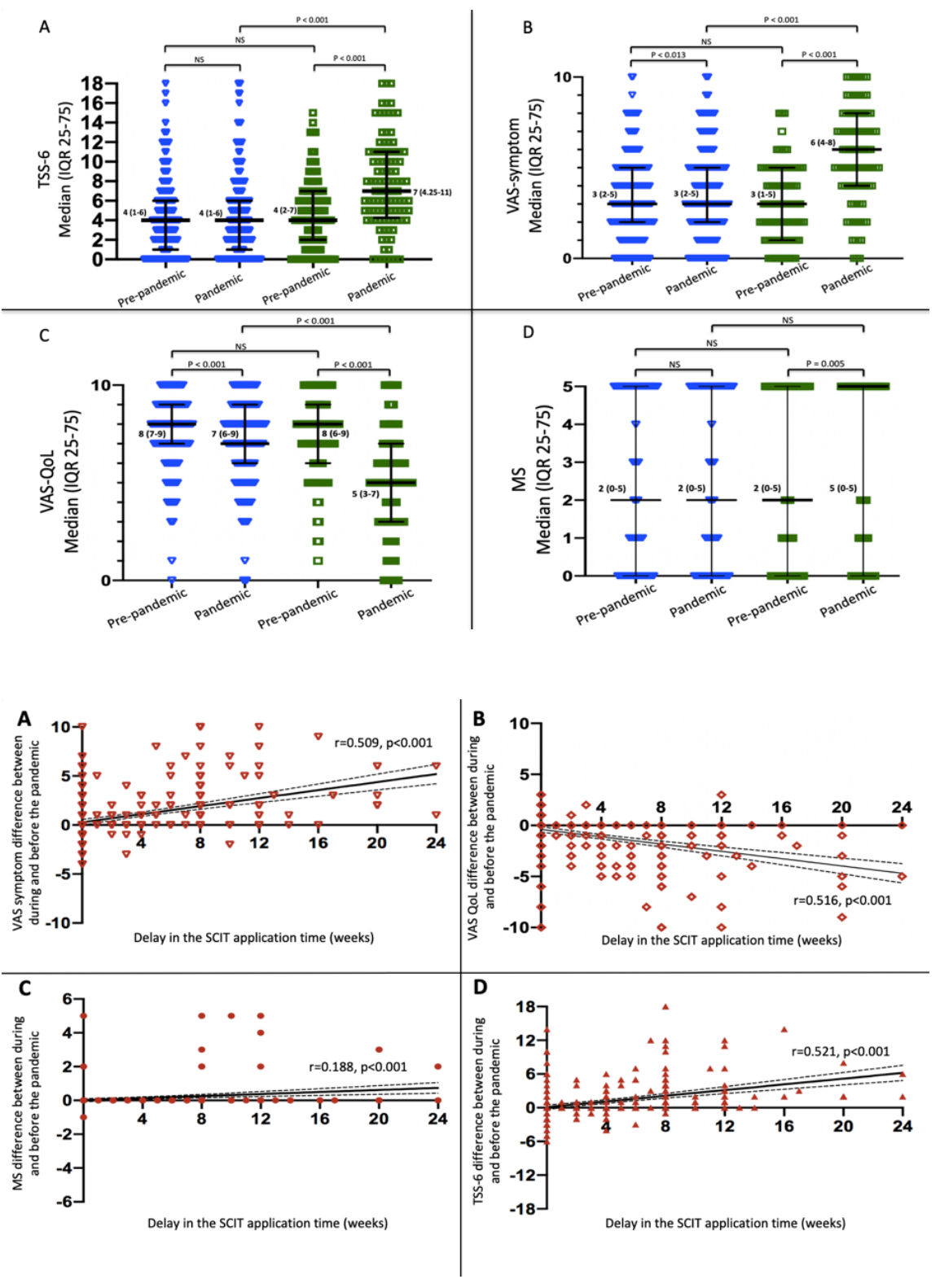